\title{
On Biastrepsis in its Relation to Cultivation.
}

\author{
BV \\ HUGO DE VRIES, \\ Professor of Botany in the University of Amsterdam.
}

T $\mathrm{N}$ his very suggestive volume 'Materials for the Study of 1 Variation, treated with especial regard to Discontinuity' (I 894), Mr. W. Bateson says (p. 574), with regard to the relation of the study of variations to the great questions of the origin of species and the operation of natural selection, ' The only way in which we may hope to get at the truth is by the organization of systematic experiments in breeding, a class of research that calls perhaps for more patience and more resource than any other form of biological inquiry. Sooner or later such investigation will be undertaken, and then we shall begin to know.'

It is hardly necessary to point out that such experiments in breeding can be much more easily carried out with plants than with animals, especially when it is necessary to have a large number of individuals under observation. This is the case at present, since selection is the chief point at issue, so that the validity of the conclusions to be drawn depends mainly on the number of the individuals in each experiment. In the case of plants it is a simple matter to raise several hundred individuals, and to retain but a few as the parents of the succeeding generation; it is a much more complicated and [Annals of Botany, Vol. XIII. No. LI. September, I899.] 
costly affair to do this in the case of animals. Moreover, it is easy to cultivate plants under quite natural conditions, whilst the breeding of rats and mice, or moths or other insects, for experimental purposes, can only be carried on under conditions which are far from being natural, and which cannot be said to be favourable to the normal development of the animals. On these and other similar grounds, breeding experiments relating to inheritance and variation can be most satisfactorily instituted with plants.

For more than ten years I have been occupied with experiments of this nature. The object which I have had in view is to study the effect of selection under the most favourable conditions in producing breeds and varieties, on the one hand; and, on the other, the influence of various external conditions upon the production and further development of these variations.

In the course of such experiments the important distinction to be drawn between individual and partial variations becomes at once apparent. The former are deviations from the type which show themselves, though not necessarily in a uniform degree, in all the homologous members of the body of an individual, as, for instance, a variation in colour of the flowers or the fruits. The latter are manifested in but few members; thus only a single leaf or flower may exhibit some special peculiarity. I have also found that the partial variations are in a much higher degree dependent upon external conditions than are the individual variations; hence the former are more useful than the latter as a means of studying the effect of external conditions.

Amongst the partial variations, fasciations and twistings of the stem are especially serviceable for this purpose. These phenomena used to be regarded as accidental monstrosities, but I have shown by breeding experiments that they are hereditary ${ }^{1}$. They are typical examples of partial variation ;

1 Ueber die Erblichkeit der Zwangsdrehungen, Ber. d. deutsch. bot. Ges., I 889, vii ; also, Monstruosités héréditaires offertes en échange aux Jardins Botaniques, Kruidkurdig Jaarboek v. h. Genootschap Dodonaea, Gent, I897, p. 62.- 
on each sufficiently branched individual some of the branches are normal; the normal branches are in fact usually more numerous than the abnormal.

A few years ago I showed, in Crepis biennis, what results can be obtained by means of selection and cultivation in the case of fasciation ${ }^{1}$; and in an earlier work ${ }^{2}$ I demonstrated that from a few isolated individuals of Dipsacus sylvestris with twisted stems a breed can be produced by selection, such that the abnormality recurs annually in a larger or smaller number of the plants raised from seed.

Such hereditary breeds or races afford the best material for comparative investigation of the conditions upon which the development of abnormalities depends. According to circumstances each successive generation is richer or poorer in so-called 'heirs'; that is, in individuals which manifest the monstrosity. If the breed is in itself poor in heirs, that is, if it shows, even after careful annual selection of the seed-producers, only a small percentage of monstrous individuals, it is one which is obviously not suitable as material for such an investigation : but if, on the contrary, under normal conditions,

[Note. The expression 'twisting of the stem,' used above in the text, is intended to render into English the term 'Z Zwangsdrehung,' applied to this abnormality by Al. Braun (Monatsber. d. k. Akad. in Berlin, I 854), for which there is no recognized Eriglish equivalent (see Masters, Vegetable Teratology); it might perhaps be well to adopt the term 'biastrepsis,' proposed by Schimper (Flora, 18 54 , p. 75). The addition of a brief description of this 'Zwangsdrehung' or 'biastrepsis,' in its characteristic form, may be of use to the reader. It occurs only in plants the shoots of which have opposite or whorled leaves; the phyllotaxis becomes spiral instead of verticillate, the successive leaves of the spiral being connected by their bases. The effect of this cohesion of the leaf-bases is to prevent the normal elongation of the internodes, which therefore become spirally twisted and often much dilated and otherwise monstrous in form. When, as is sometimes the case (e.g. Dipsacus), the stem is hollow, the pith-cavity is normally interrupted by diaphragms at the successive nodes; but in the twisted stems the pith-cavity is continuous, the diaphragms of the normal stem being represented by a rib projecting into the pith-cavity and following the course of the leaf-spiral.-ED.]

1 Sur les courbes Galtoniennes des monstruosités; Bull. Scientif. de la France et de la Belgique (Giard), 1896, t. xxvii, p. 396 .

${ }^{2}$ Monographie der Zwangsdrehungen, Pringsheim's Jahrb. für wiss. Bot. xxiii, I 89I. See alsc, 'Eine Methode Zwangsdrehungen aufzusuchen,' Ber. d. deutsch. bot. Ges. xii, 1894; and 'Bijdragen tot de leer van de Klemdraai,' Kruidkundig Jaarboek, Dodonaea, iv, $189^{2}$, p. 145 . 
say one-third of the progeny show the variation, whilst the remainder are atavistic, it may be anticipated that changes in the external conditions will manifest their influence by causing fluctuations in this percentage.

On this principle are based the investigations which I purpose to describe in this paper, and which were almost exclusively carried out with my twisted breed of Dipsacus sylvestris, after this had attained in the fourth generation a degree of heredity exceeding 30 per cent.

The publication of the results which I have obtained during the last six or eight years has, furthermore, a practical object. I am convinced that the cultivation of this twisted breed, if generally adopted, would afford an easy means of investigation. Since I showed that monstrosities in plants are, as a rule, hereditary, and more particularly that twisted forms can be cultivated in Botanic Gardens as hereditary breeds, investigations have, as a matter of fact, been made in various places. But it has become apparent that the cultivation of such breeds is not so simple a matter as it appeared to be at first. Whilst some botanists have succeeded in raising from seeds obtained from me as striking and as numerous monstrous specimens as I myself, others have been less successful.

The cultivation of plants having twisted branches, fasciations, \&c., makes greater demands on the gardener than that of normal plants of the same species. These monstrosities are, in the first place, only partial and not individual variations ; certain parts only of the body deviate from the type in the given direction. Some parts only show the abnormality, and in the case of twisting (biastrepsis) it has so far been observed to extend over a larger or smaller area of the main stem or of the branches.

Individual variations are obtained pure from pure seed; the conditions of germination and of subsequent cultivation have no effect upon this. Hence their cultivation does not involve anything more than that of the species to which they belong. However, it often happens that the seed, obtained by exchange or by purchase, is not quite pure, and therefore 
selection by weeding out may have to be exercised. Partial variations, on the other hand, depend almost as much upon the cultivation as upon the seed. The purest seed is no absolute guarantee for a satisfactory batch of seedlings, unless the treatment has been appropriate. Then again, in the more familiar breeds, rarely more than one-third of the individuals exactly reproduce the abnormality, the others reverting more or less completely to the type.

With regard now to the raising of plants with partial variations. The seed must, of course, be taken from those members of each generation which show the abnormality (twisting, fasciation, \&c.) in the highest degree. The plants selected as seed-bearers must be isolated before flowering, either by digging up all the rest or by removing all their flower-buds. In their cultivation the following points must be regarded. In the first place the sowing must be made at the proper time, usually in April ; it is best to sow in pans under glass. The seedlings should be pricked out when they have developed the second leaf, and should either be planted out at once in their ultimate position, or be kept singly in pots for a few weeks (pots of $8-10 \mathrm{~cm}$., or 3 in., are the best). Further, most monstrous plants require an open, sunny situation, plenty of space, and much manure. The attempt should not be made to grow the plants in a shady place; sometimes it may be successful, but the result is very uncertain. The plants should, from the very beginning, be planted so far apart that they do not touch or overshadow each other at all, or at least not until they have grown so far that the monstrosity has made its appearance. The amount of manure required obviously depends upon the nature of the soil, but it can hardly be given in excess. I made use of dried cow-dung, so-called cattle-guano, and horn-meal (crushed and steamed horns and hoofs), and gave $\frac{1}{2}-\mathrm{I}$ kilog. of this mixture to every square metre of soil. The seed-pans must not be manured at all, otherwise Botrytis cinerea, the great enemy of all special cultures, will be developed.

I propose to describe now a series of experiments, all of 
which were made with my twisted breed of Dipsacus sylvestris. As I have already remarked, this breed, with proper treatment, gives a progeny $30-40$ per cent. of which have wellmarked twisting of the main stem, besides other individuals which show less marked twisting of the branches, and others again which have their leaves in whorls of three. If, however, the treatment is unsatisfactory as regards any one of the essential conditions mentioned above, this high percentage of monstrous forms is not obtained; there may, in fact, be none at all.

The scientific results of my experiments may be summed up by saying that Biastrepsis, especially in the case of Dipsacus sylvestris, is in a high degree dependent upon the conditions which obtain during and subsequently to the germination of the seed. Conditions which favour the vigorous development of the plants promote also the size and the number of the portions of the main stem and of the branches which show the twisting.

The practical result of my experiments is, I consider, the recognition of the fact that the cultivation of monstrosities should either be carried out strictly according to rule, or not be attempted at all. Without the requisite care the attempt only results in doubt being cast upon the goodness of the seed and the hereditary properties of the breed.

I treat of the subject under the following heads :-

$A$. The normal cultivation of the breed.

$B$. The influence of space.

$C$. The influence of the soil.

$D$. Summer-sowings.

$E$. Autumn-sowings in the open.

$F$. Autumn-sowings under glass.

$G$. Cultures in other Botanic Gardens.

A. The Normal Cultivation of the Breed.

In my monograph on the subject (I89I), to which allusion has already been made, I have given an account of the morphology of biastrepsis in Dipsacus sylvestris, and of the 
means by which I obtained the hereditary breed. I was then in a position to report upon the first four generations of this biennial; I now give the results of my observations on the subsequent generations.

My breed was derived from two individuals with a twisted main stem, which made their appearance among plants obtained from a sowing in I884. Before they flowered, all the other individuals had been removed. From the seed of these two I obtained the second generation in I885. At that time I was unaware of the special conditions essential to the successful cultivation of these plants, and, doubtless on this ground mainly, I found only two twisted individuals among about 1650 seedlings. Both of these flowered in isolation, and bore seed abundantly. From this seed the third generation was raised in I 888-9, consisting of about the same number of plants, among which were sixty-seven with twisted stems, that is, about 4 per cent. of the total number. The seed-bearing plants selected were flowered in isolation.

The seed for the fourth generation was sown, in part, in I 890 , and gave about 10 per cent. of twisted individuals, which, owing to an accident, could not be used for the propagation of the breed. The remainder of the I888-9 seed was therefore sown in $189 \mathrm{I}$, and, with a better knowledge of the requisite conditions, I obtained 34 per cent. of twisted individuals, a percentage which has been approximately maintained, but not materially exceeded, in subsequent generations.

The improvement in the method of cultivation was essentially this, that more space was allowed to the young plants from the very beginning. In the two previous generations about fifty individuals were grown to the square metre; in this generation the number was reduced to about twenty-five by the repeated weeding-out, during the month of June, of all superfluous plants so soon as they began to touch one another.

The sowing on the beds was done in the middle of May, 189I. At the beginning of October I found that about half a dozen plants in every hundred had spiral phyllotaxis 
within the dense rosette; and at the beginning of November I had rather more than half of the plants removed as being undoubtedly normal and atavistic. Towards the end of May, 1892, when the shoots were being vigorously pushed up, the plants were finally gone over and counted. Including the figures for the previous November, I obtained the following result for the whole sowing :-

\begin{tabular}{ll} 
Twisted stems & $37=34 \%$ \\
Stems with $\frac{1}{3}$ phyllotaxis & $12=11 \%$ \\
Normal.(atavistic) & $58=55 \%$ \\
\multicolumn{1}{c}{ Total } & $\frac{58}{107}$
\end{tabular}

It is of importance to remark that the number of twisted individuals had increased, with the larger space, not merely relatively in percentage but absolutely per square metre. In the third generation there were fifty plants to the square metre of which 4 per cent. ( $I-7$ per cent.), or about $I-4$ plants, were twisted: in the fourth generation I had four square metres with thirty-seven twisted individuals, that is, about nine to the square metre.

I selected from this bed the seven best plants as seed-bearers, all of them having local biastrepsis in some of the branches, and I isolated them before flowering.

The fifth generation, I 893-4, gave less favourable results: it yielded only 20 per cent. of twisted main stems. In this case I had not, as previously done, sown the seed on the beds, but in pans standing in the greenhouse of my laboratory. This method has since proved itself to be the more convenient and certain, and it was adopted with both the succeeding generations.

The seed harvested in September, 1892 , was sown in the middle of March, 1893 . A bout the middle of April the best seedlings were transplanted singly into $10 \mathrm{~cm}$. pots, containing well-manured loam; and about the middle of May they were planted out in the beds at about the same distance from each other as in the previous experiment (twenty-two plants to the square metre). In the next year all the shoots 
shot up, and on counting them the following results were obtained :-

\author{
Twisted main stem \\ Phyllotaxis $\frac{1}{3}$ \\ Normal (atavistic) \\ Total
}

\begin{tabular}{rrrr}
$A$ & $B$ & $\% A$ & $\% B$ \\
5 & 2 & 20 & 10 \\
$\mathrm{I}$ & $\mathrm{I}$ & 4 & 5 \\
19 & $\mathrm{I} 7$ & 76 & 85 \\
\hline 25 & 20 &
\end{tabular}

$A$ and $B$ are two groups of plants grown from seeds specially collected from two of the 1892 seed-bearers.

The number of plants is obviously too small to admit of attaching much importance to the percentages obtained.

In the autumn of 1894 the seed of the four best plants, which had been isolated from the rest, was harvested.

The sixth generation, $1895^{-6}$, yielded a much more satisfactory result, viz. 42 per cent. of individuals with twisted main stems; a result which was due, in part at least, to the greater distance of the plants from each other, the other conditions of cultivation being as before. The seed of 1894 was sown about the middle of March, 1895 , in pans kept in the greenhouse, the seedlings being transplanted into pots early in April, and planted out in the beds at the beginning of May. But there were only thirty-three plants to four square metres, that is about eight to the square metre. At the end of October I found that fourteen of the leaf-rosettes showed spiral phyllotaxis in the centre, seven showed $\frac{1}{3}$ phyllotaxis, and twelve were normally decussate ; that is, 42 per cent. had spiral and 21 per cent. $\frac{1}{3}$ phyllotaxis, and $3^{6}$ per cent. were decussate. In May, I896, I confirmed this result, and then all but the spiral plants were weeded out. The six most strongly twisted individuals were selected as seed-bearers, and were isolated before flowering.

The seventh generation, $1897-8$, was raised in much the same way. The seed of 1896 was sown in the greenhouse on May 5, I 897 ; the seedlings were potted off, and about the beginning of July they were planted out, seventy in all, in the beds, sixteen plants to the square metre. 
At the end of May, 1898 , I found that these consisted of -

Plants with twisted stems
,,$\quad \frac{1}{3}$ phyllotaxis
,$\quad \quad$ normal decussate

Total

$$
\begin{aligned}
& 32=46 \% \\
& 2 I=30 \% \\
& \frac{I 7}{70}=24 \%
\end{aligned}
$$

The proportion of stems in which the twist was to the left or to the right respectively was maintained unaltered in this generation, there being usually about an equal number of the two kinds, as shown in the following table :-

\begin{tabular}{|c|c|c|c|c|}
\hline Generation. & Sowing. & $\begin{array}{l}\text { No. of } \\
\text { plants. }\end{array}$ & $\begin{array}{c}\text { No. to } \\
\text { square metre. }\end{array}$ & $\begin{array}{l}\text { Percentage of } \\
\text { twisted stems. }\end{array}$ \\
\hline I. $1884-5$ & Bed & - & - & - \\
\hline 2. $1886-7$ &, & 164.3 & - & 0.1 \\
\hline 3. I $888-9$ & , & I6I 6 & 35 & 4 \\
\hline 4. $189 I-2$ & , May ${ }_{5}$ & 107 & 25 & 34 \\
\hline 5. $1893-4$ & House, Mar. I 7 & 45 & 22 & IO-20 \\
\hline 6. $1895^{-6}$ & Mar. II & 33 & 8 & $4^{2}$ \\
\hline 7. $1897-8$ & May 5 & 70 & I6 & 46 \\
\hline
\end{tabular}

$\begin{array}{llll}3^{\text {rd }} \text { generation, } 1889 & 29 \text { right } & 27 \text { left } \\ 4^{\text {th }} " & 189^{2} & 2 \mathrm{I} ", & 33 ", \\ 7^{\text {th }}, & 1898 & 14 " & 17 \%\end{array}$

The whole history of the breed may be summarized in a tabular form as follows :-

Whilst at first a large number of plants, crowded together, were used with imperfect success, in the later years fewer plants with plenty of space have afforded much more satisfactory results. This improvement is due in part to the more favourable cultural methods, in part to the continuous selection ; it is impossible in this case, as usually in other such cases, to discriminate between the effects due to these two causes respectively. It will, however, be shown in the next section that the better cultural methods were of considerable importance in bringing about the result.

\section{B. The Influence of Space.}

The condition most essential to the successful cultivation of these twisted plants is that each plant shall have sufficient room in which to develop freely; the plants must neither 


\section{Relation to Cultivation.}

touch nor overshadow each other. This result is clearly indicated by the various cultures previously described.

It is instructive, in connexion with this point, to compare the plants growing on the borders of a bed with those growing in the middle. Whenever the space becomes insufficient, the twisted stems are mostly or even entirely confined to the plants growing on the borders: this was the case in the second and third generations, when there were about fifty plants to the square metre. On the other hand, the occurrence of spiral rosettes in the plants on the borders, and the absence of them from those in the middle of the bed, is one of the best indications whether or not the plants have sufficient space allotted to them.

In order to demonstrate in a simple manner the truth of the above statement, I instituted the following experiments.

In 1889 seeds, obtained from the second generation in I887, were sown on two neighbouring beds and in the same manner. When, in June, the plants began to touch each other, they were not thinned out to an equal extent; on the one bed 300 plants were left, on the other 540 . As each bed had an area of twelve square metres, there were in the one case twenty-five plants to the square metre, in the other fortyfive. On examining the elongated shoots in May of the following year the results, which were widely different in the two cases, were-

Bed, 25 plants to square metre
Bed, 45 plants to square metre
"

$6 \%$ twisted stems.

$5 \%$ phyllotaxis $\frac{1}{3}$.

$\mathrm{I} \%$ twisted stems.

$1 \%$ phyllotaxis $\frac{1}{3}$.

I made a second experiment, in which the plants were still more crowded together. In the first summer I allowed 136 plants to grow on a bed of $2 \cdot I$ square metres area, that is, sixty-five plants to the square metre. In order to eliminate the effect of the border-position, I surrounded the bed with a margin of plants placed about as closely as the others, but these marginal plants were not subsequently counted in with the others. When I examined the rosettes in the following 
February, no trace of spiral arrangement could be detected. A control-experiment, with sixty-two plants from the same seed, but planted twelve to the square metre, gave io per cent. of individuals with twisted stems.

Hence lack of sufficient space can entirely prevent biastrepsis from making its appearance.

A similar result was obtained with regard to the exposure of the beds. Shade, whether of trees or other objects, is always prejudicial; a good proportion of twisted stems can only be obtained when the plants are grown in an open situation fully exposed to the sun. Thus, in I 890 , a sowing in the shade of a tree gave only 3 per cent., whilst another quite similar sowing, but with full exposure to the sun, gave 7 per cent. of plants with spiral phyllotaxis.

The time for sowing the seed, whether in the open or in pans in the greenhouse, varies from March to the beginning of May. The time and mode of sowing seems to be of little or no importance as compared with the requirement of sufficient space.

When sowing in the open, about 3-5 c.cm. of seed per square metre should be used, containing 200-300 seeds. Of these only a portion will germinate, and of these some are lost or are weeded out, so that eventually only about 20-25 plants result. On the other hand, seeds sown in pans kept in the greenhouse nearly all germinate; the seedlings are very uniform, and can be potted off without any selection. The latter method therefore yields by far the more reliable figures of the two.

In weeding out the seedlings obtained by sowing in the open, either the most vigorous plants may be left, or no attention may be paid to this point; but the result is materially influenced by the course pursued, for the weaker plants are much less likely than the vigorous to show twisting. They are plants which apparently have been badly nourished, either in the seed-stage whilst still on the parent, or during or after germination. I made an experiment on this point in I888-9. In June, I888, I planted two similar 
beds, each of 12 square metres area; the one with 360 very vigorous plants, the other with 410 weakly plants, from seeds of the same parent. The weakly plants were small, and therefore required less space. When the plants shot up in the following year, the one bed gave 8 per cent., the other only 3 per cent. of twisted stems.

\section{INFLuence of the SOIL.}

The richer the soil, and the more vigorous the plants, the better is the prospect for a high proportion of twisted stems.

In the year I 89I, in addition to the culture on good loose soil (see p. 40I), I had a control-experiment on poor hard ground. The good soil was manured with 2 kilog. of guano and dried cow-dung per square metre; the poor soil received only one-eighth of a kilog. of guano per square metre; the treatment in other respects was identical. The result was-

$$
\begin{aligned}
& \text { On the good manured soil } \\
& \text { On the poor soil }
\end{aligned}
$$

$34 \%$ twisted stems$$
14 \% ", "
$$

In very poor soil the proportion of twisted stems may sink to nothing. I made an experiment of this kind in I894 with a bed which consisted, to a depth of half a metre, of nothing but sand. For seed I used two samples, gathered in I89I and 1893 , which gave, in control-experiments, Io per cent. and $25-30$ per cent. of individuals with spiral phyllotaxis; half a bed (4 square metres) was sown with each of the samples. The seeds were covered with garden-soil in order to ensure germination. The two half-beds gave respectively 94 and 124 plants, that is 24 and $3^{I}$ per square metre, which, as they were for the most part small, only touched each other here and there. The plants were examined in May, 1895 , and it was found that, without exception, the phyllotaxis was decussate.

This is a convenient opportunity to direct attention to a circumstance which has hitherto been insufficiently recog- 
nized in comparative experiments with plants : I refer to the inequality of external conditions as regards the individual seedlings growing on one and the same bed. This inequality is much greater than might be supposed, especially during germination. It is a familiar fact that the seeds of a sowing do not all germinate simultaneously; and those which germinate on a sunny day in moist soil are at a great advantage as compared with those which germinate in dry soil or on a dull day. The unevenness of the surface of the soil leads to some spots being dry and others relatively moist, and germination is so much expedited in the latter that the seedlings are often found growing in scattered groups. The mixture of the soil with the manure is not uniform, even when the greatest care is taken; and this leads to an unequal distribution of moisture in the soil, especially when fresh farmyard manure is used. Then again, injury by birds or insects gives rise to great differences among the seedlings. All these various conditions have as their result that the young plants, after germination is over, soon show striking differences in development. According to the goodness or badness of the weather in the course of the summer, these differences either become more marked or they tend to disappear. And then, if the plants are crowded so as to touch each other, the existing differences become accentuated, the more vigorous developing rapidly at the expense of the weaker.

Much more in the same strain might be added: but what has been said suffices to prove that the individual differences between plants growing on the same bed are mainly caused by the inequality of the conditions under which they have been developed. If now the most vigorous and best-developed individuals be selected as seed-bearers, it is almost certain that they are those which have been the most highly nourished throughout their lives. Selection in this case means the selection of the best-nourished.

It would appear to be quite permissible to extend this conclusion to the case of biastrepsis. During the ripening of the seeds, during their germination, and then during their 
subsequent development, the individuals of the same sowing of the same seed are exposed to very different conditions of life, although every effort may have been made to secure uniformity in this respect. And it is these differences of external conditions which determine which and how many of the seedlings shall develop twisted stems, the seedlings belonging, of course, to the proper hereditary breed.

The plants with the most strikingly twisted stems which are selected as the seed-bearers are thus generally those which have been the most highly nourished. And as this mode of selection is pursued in successive generations, so the best-nourished plants have for many years had the bestnourished individuals as their ancestors. Thus the influence of nutrition accumulates as the generations succeed each other.

I may add that I have made similar observations in the case of other plants and of other types of monstrosities.

\section{Summer-Sowings.}

The sowings associated with the observations which have been already given were made between the beginning of March and the middle of May, and the particular time of the sowing was without influence upon the percentage of twisted stems. Under proper treatment the plants come on so vigorously in the course of the summer that whatever differences may have originally existed gradually disappear, so that they cannot be detected in the winter or in the second summer after the sowing has taken place.

Dipsacus sylvestris torsus is strictly biennial. In spite of careful observation, I have been unable to discover any annual individuals. I obtained seeds of $D$. sylvestris from various Botanic Gardens and made large sowings, but in no case did an annual form occur. This is the more remarkable since most biennials (such as Beta, Daucus, Oenothera) produce numerous individuals which 'bolt,' from which an annual 
breed can easily be raised. Under these circumstances the question arises, What would be the effect of sowing the seed, not in the spring, but in summer or in autumn? and I have endeavoured to find an answer to this question by the experiments of which the following is an account.

Seeds were sown in the summers of 1892 and 1893 , at the beginning of June, at the end of July, and in the middle of August. The seed used belonged to the fourth or fifth generation of my breed which had already attained 34 per cent. of twisted main stems. The chief result was that the plants obtained by summer-sowing regularly developed their shoots in the following year; but, with the exception of a single individual of the June sowing, the stems were not twisted. The details of the various cultures are as follows :-

Sowing of Fune I, 1893 . The seed was that of 1892 , from a crop which contained 34 per cent. of twisted stems; it was sown in rows on the bed. The seedlings came up regularly; and up to October superfluous plants were weeded out so soon as they began to touch one another. About twenty plants per square metre remained, so that the condition of space was very favourable (see p. 404); there were I79 plants in 9 square metres. In May, 1894 , all the rosettes shot up without a single exception. As soon as the phyllotaxis of the shoot could be made out, the plants were examined. One stem was found to be characteristically twisted, another had three-leaved whorls, whilst all the others had the normal decussate phyllotaxis and showed no twisting of the stem.

All the plants, with the exception of the twisted individual, were dug up. This plant clearly showed itself, in the course of the summer, to be less vigorous than the twisted individuals of a normal culture, and it flowered later. Its stem was twisted right up to the inflorescence.

Sorving of Fuly 28, 1892. Seeds harvested in 1891 were sown on a bed having an area of 4 square metres, and the soil was kept moist by means of a lawn-sprinkler. The seeds germinated rapidly, and before the autumn had formed vigorous rosettes of radical leaves. By the end of the follow- 
ing May all the seedlings, with the exception of a few weakly ones, had thrown up their shoots. When the shoots had attained a length of $50-75 \mathrm{~cm}$., and the terminal capitulum could just be seen, it was found that all the plants were quite normal, having decussate phyllotaxis ; the only observable abnormality was one divided leaf. There were I 3 I plants with elongated shoots, and twenty-nine with only rosettes, 160 plants in all, on the 4 square metres, so that the proportion (forty) per square metre was high; but this number did not appear to be excessive, inasmuch as the plants were relatively small and did not touch each other more than would vigorous plants at a greater distance from each other. After the counting was done, I allowed five of the best specimens to remain; they developed strong stems over 2 metres high, which were not noticeably less vigorous than ordinary normal plants of the breed.

In a control-experiment made with the same seed sown in the spring of 1892 , I obtained twenty-two individuals out of sixty, that is, almost 37 per cent., having twisted stems.

Sorving of August 14, I 893. The seed used was obtained from two plants of the 1892 crop, and was the same as that used in the June sowing of this year. They quickly germinated in the bed, and by the autumn had formed relatively small rosettes, so small, in fact, that sixty plants per square metre could well be left. Notwithstanding this, they nearly all (235) threw up their shoots in the following spring; but here and there, where germination had been tardy, some plants, twenty in all, remained as rosettes, that is, about 8 per cent. The stems were weak, of only about half the normal thickness, and their leaves were decussate up to the inflorescence; there was no sign of twisting of the stem.

Summarizing these results of summer-sowing, we find that, given adequate space and suitable treatment, there is an almost entire absence of twisted stems. The experiments included I79, I3I, and 235 plants, giving a total of 545 shoots, of which only one was twisted and one had threeleaved whorls, both of these exceptional plants belonging to 
the June sowing. In contrast with this, the spring-sowings gave 34-37 per cent. of twisted stems.

I conclude, therefore, that late sowing does not allow the plant sufficient time in which to attain normal vigour in the rosette-stage. Hence, when the shoots are thrown up, they are too weakly to develop spiral phyllotaxis. This result accords fully with those obtained in my observations on the effects of too limited space and bad soil.

\section{E. Autumn-Sowings in the Open.}

I began an experiment on September I I, 189I, which may be regarded as a control to the summer-sowings. The seedlings which are produced in a sowing so late in the season do not throw up their shoots in the following year, but remain in the rosette-stage, the plants growing vigorously until the following autumn. They do not throw up their shoots until the third year. The lateness of the sowing has, therefore, the effect, not of weakening, but of materially invigorating the plants.

At the beginning of the first winter the young plants had only two or three pairs of leaves, which were not much more than $3 \mathrm{~cm}$. in length. It is known that the throwing up of the shoot of biennials in general is the result of stimulation, and that this stimulation is given by the winter. Indeed, when Rape is sown early, this effect may be produced by the late night-frosts. But if the plants are too young they appear not to be susceptible to this stimulation. This is a phenomenon which has been too much overlooked by physiologists.

In the middle of September, 1892 , just one year after sowing, I examined the plants. There were twenty-three of them in a small bed of 2 square metres area. Not one of them had thrown up a shoot; but ten of them ( 44 per cent.) showed spiral phyllotaxis in the heart of the rosette, and four had three-leaved whorls. 
Hence it appears that the effect of the prolongation of the rosette-stage is rather to increase than to diminish the proportion of abnormal plants. Moreover, this experiment leaves no doubt as to the correctness of the interpretation which I have placed upon the results of summer-sowing.

\section{F. Autumn-Sowings in the Greenhouse.}

The object of these experiments was so to accelerate, by cultivation in a greenhouse under favourable conditions of temperature, illumination, \&c., the germination of the seeds and the subsequent growth of the seedlings during the autumn and the winter, that the plants should be in a position to throw up their shoots in the following summer. In order to maintain the earth in the pots, day and night, as nearly as possible at the temperature $\left(22^{\circ} \mathrm{C}\right.$. $)$ which I found to be most suitable, I made use of a large shallow water-bath, $10 \mathrm{~cm}$. in thickness, which occupied a closed space in the small greenhouse attached to my laboratory, and was distant only $20-25 \mathrm{~cm}$. from the glass above it, being inclined so as to be about parallel to it. The pots were $10 \mathrm{~cm}$. in diameter; each either contained a single plant from the beginning, or two plants, the weaker of which was removed so soon as they began to touch each other. By a control-experiment it was ascertained that it would not suffice to heat the water-bath only during the day-time; plants treated in this way threw up no shoots in the following summer. Continuous heating was required, and this was carried on from the middle of September, when the sowing took place, until the middle of November, at which time the seedlings had five or six pairs of leaves, the leaves being about $14 \mathrm{~cm}$. in length.

The experiments were begun on September I7, I 892, and on September 15, 1893 , the seed used being in each case that which had just before been harvested. With the success of the experiments the whole life-cycle of these biennial plants was brought within the limits of a single year; and it would 
eventually become possible thus artificially to grow them as annuals, and perhaps in time to establish an annual variety by selection.

Sowing of September I7, I892. The seed was harvested and sown on the same day: it was obtained from a plant the seeds of which gave 20 per cent. of twisted stems when cultivated in the ordinary way. Germination and the early stages of growth were quickly and satisfactorily gone through. The water-bath was heated until the middle of November; subsequently only the greenhouse was heated. At the end of January, I 893 , the plants were put out into a cold frame, where they proceeded to form new leaves, those which had been formed in the greenhouse now dying off. In the middle of March they were planted out, and after the middle of April they were no longer protected by glass.

At the beginning of June there were nineteen plants with vigorous shoots $50-75 \mathrm{~cm}$. in height, and twenty-two rosettes. At the end of June the nineteen shoots were nearly two metres in height, and were as vigorous as average plants of my breed. The examination of these shoots showed (1) that eight of the plants had normal decussate phyllotaxis; (2) that there were seven plants which, although their phyllotaxis was decussate, had each a four-leaved whorl owing to the suppression of an internode; (3) that there were four plants with slight and local twisting in the shoots which were otherwise straight. One of these showed well-marked twisting in one of the lateral branches. Hence only four plants out of nineteen (about 20 per cent.) showed slight and local twisting of the stem; that is, just the same proportion as that of typically twisted stems occurring in a control-experiment ${ }^{1}$. These four plants flowered in isolation and ripened seed before September 15, 1893 ; that is, within a year from the time of sowing.

\footnotetext{
1 It should be remarked that in the control-experiments only the entirely, or almost entirely, twisted stems are counted : no attempt was made to ascertain whether or not slight local twisting of the stem would develop in the other plants, for most of these were dug up before they had completed their growth.
} 
The effect of the method of culture described above is that, in these artificially annual plants, whilst twisting of the stem is not altogether prevented, it is reduced to a minimum.

Sorving of September 15, 1893. The seed of one of the previously described artificially annual plants was immediately sown, and germination took place under the same conditions as in the previous year. The seed-bearing plant was the one which showed twisting in one of its lateral branches. At the end of January the plants were brought out of the greenhouse and were kept for a time under glass. Two weakly plants remained in the rosette-stage, but the others, thirty-five in number, threw up shoots in May: the shoots were vigorous, of about the same height and thickness, and were better and more uniformly developed than were those of the preceding generation. The examination of them on June 18 gave the following results :-

Nine normal decussate shoots ;

Ten decussate shoots, each having one four-leaved whorl ;

Three shoots with two four-leaved whorls;

One shoot with three four-leaved whorls;

One shoot in which the leaves of one of the pairs were separated.

Eleven shoots with slight local twisting ( $3 \circ$ per cent.).

The result is thus the same as that obtained with the preceding generation. I was unable to allow these plants to flower, for fear of interfering with the normal cultivation of the breed.

Sowing of September 3, I 894. Professor G. Le Monnier of Nancy, who has for years cultivated my breed of Dipsacus on a larger scale than I have myself been able to do, was good enough to send me some freshly-gathered seed of twisted individuals early in September, I 894. In the more southerly clinate of Nancy the seed had ripened a fortnight earlier than with me ; consequently I was able to repeat the experimental sowings of the two previous years with this new and favourable factor. The plants grew more rapidly than those of previous years on the heated water-bath, and by the middle 
of November had formed about twice as many leaves. They were kept warm until the middle of December, when they were taken out and put under glass. By the end of May they had all (thirty-six) thrown up their shoots, but these shoots were decussate right up to the inflorescence.

In a control-experiment made with the same seed, but without artificial heat, the plants were potted off soon after germination and were kept under glass in the garden : twentynine of them threw up stems in the following year, which, as was to be expected, were decussate ; nine plants remained in the rosette-stage.

The conclusion to be drawn from all these experiments is that whilst it is possible to contract into one year the lifecycle of the biennial Dipsacus sylvestris torsus, by sowing the seed immediately it is ripe and by hurrying on germination and the early stages of growth, this takes place at the cost of the biastrepsis, which is either altogether wanting or is manifested in only a relatively slight degree.

\section{$G$. Cultures in other Botanic Gardens.}

When, in the summer of 1889 , the third generation of my breed began to show a distinct increase in the percentage of twisted individuals, I distributed seed of it for the first time; and I did so at the friendly request of Professor J. Urban of the Botanic Garden at Berlin. So successful was the cultivation of the breed there, that in the published catalogue of the seeds gathered in $189 \mathrm{I}$ there are enumerated no less than five varieties of these plants with twisted stems or with threeleaved whorls. Since then I have distributed seed in increasing quantity, and the cultivation of the breed has been successfully carried out in various Botanic Gardens, although in some cases difficulties have been encountered. The plant requires not only a good deal of space, open exposure, and loose wellmanured soil, but special attention in addition, which is often begrudged since the species grows wild and is to be met with 
even in overgrown localities and on bad soil. Carefully raised garden-plants are, however, much more sensitive than wild ones, and with this the tendency to biastrepsis is intimately connected. For instance, the cultivated plants are often killed by frost in damp winters with us, or only the main flowering shoot is killed. In the latter case lateral shoots are thrown up in the following summer which usually show but little twisting; but the plants may be used as seed-bearers. The plants should therefore be protected during the winter, if there is no snow, with straw or leaves. A single dead leaf placed over the crown of the rosette suffices to protect, if only it is kept in position, and does no harm however long it remains.

The most detailed report which I have received regarding the cultivation of this breed is that of Professor Le Monnier, the Director of the Botanic Garden in Nancy, who most kindly co-operated in some of the experiments already described. Since 1892 he has annually raised several hundred plants of my breed, and cultivated them under the most favourable conditions. In November of that year he had 490 plants in the rosette-stage, of which 20-30 per cent. showed spiral phyllotaxis, and 60-65 per cent. had three-leaved whorls, so that there were very few atavistic individuals. The proportion of twisted stems agrees with my own observations (see p. 404); but the number of plants with three-leaved whorls far exceeds anything that I have, even now, obtained in Amsterdam. Moreover, the spiral phyllotaxis appeared earlier in Nancy than in Amsterdam : it was detected there in many rosettes as early as July; but with me, even in early sown plants, it could never be seen before August, and, in the case of April or May sowings, not before September.

Professor Le Monnier had also the goodness to repeat at Nancy the experiment of sowing the seed immediately after it is ripe. This was done at the beginning of September, I894: the seedlings grew in the open, without any artificial heat, more rapidly and vigorously than they did at the same time in Amsterdam when all possible care was lavished upon them (see p. 4I5). Nevertheless in the following year they threw up 
shoots which showed no trace of twisting or of three-leaved whorls. At Nancy, as at Amsterdam, the production of seed within a year could be induced, but at the expense of biastrepsis.

The seed, gathered at Nancy, sown in 1897 , gave in the following summer only seven twisted stems, and ten with three-leaved whorls, out of about Ico shoots. This remarkable state of affairs must probably be ascribed, as Professor Le Monnier suggests, to the pollination of the twisted seedbearing plants of 1896 by pollen brought by insects from other plants of Dipsacus growing at a distance. This experience is the more important since I have myself observed that an interval of 100 metres is often insufficient to prevent the crossing of two varieties of the same species if in flower at the same time.

\section{CONCLUSIONS.}

I. The seed of Dipsacus sylvestris torsus yields, under proper cultivation, a progeny of which about one-third have twisted stems. This proportion was first attained in the fourth generation, and since then it has rather increased than diminished on the whole (see p. 404).

In addition, there occur plants with three-leaved whorls, with divided leaves, or with local twisting of the lateral branches, and occasionally the other anomalies which I have described in my monograph ${ }^{1}$.

2. The development of biastrepsis, that is, the transition from decussate to spiral phyllotaxis, depends not only upon the hereditary properties of the individual latent in the seed, but also in a high degree upon the external conditions under which the individual develops.

3. The more favourable the conditions of life, and con-

${ }^{1}$ In addition to the references given on pp. 396 and 397 , I may mention the following papers which I have published on this subject: Ber. d. deutsch. bot. Ges., xii, I894; and Kruidkundig Jaarboek van het Genootschap Dodonaea in Gent, iii, 1891 , and iv, $189^{2}$. 
sequently the more vigorous the growth of the plants, the richer is the progeny obtained from any given seed in individuals with twisted stems, and the more marked is the twisting in the individuals.

4. The most important condition is that the plants shall have plenty of space for their growth : they must not overshadow each other, and they should touch each other as little as possible. There ought never to be more than 20-25 plants to the square metre; and even then the plants come into contact with each other in the autumn: it would be better not to have more than IO-I 5 plants per square metre.

When too closely planted, the number of plants with twisted stems per square metre is less than that obtained with more remote planting; so that the greater number of individuals is not an advantage but a disadvantage. In the case of close planting, the twisted individuals are confined, either exclusively or for the most part, to the border of the bed.

5. The time of sowing is of importance, for this determines the length of life of the plant up to the time when the shoot is thrown up: the longer this period, the conditions being favourable, the greater is the prospect for biastreptic individuals.

Sowings in the summer or in the early autumn yield seedlings which throw up shoots in the following year, which shoots show little or no tendency towards biastrepsis. On the other hand, good results are obtained from autumnsowings, yielding plants which do not throw up their shoots until the next summer but one, and have therefore a longer rosette-stage : the proportion of biastreptic plants is in this case rather larger, if anything, than in the case of ordinary spring-sowings.

With regard to the spring-sowings, it does not appear to be a matter of great importance whether the seed be sown in March, in April, or early in May; or whether the seed be sown directly in the beds, or in pans in the greenhouse, the seedlings being subsequently planted out. For various reasons 
I have for some years adopted the latter method; it is more convenient, and it is more certain, especially when the spring is dry.

6. Good, loose soil, well manured with nitrogenous matter, is an important essential. On unmanured sandy soil it is impossible to raise, even from the best seed, any twisted individuals; if the soil is hard or unfertile, the percentage of such individuals diminishes.

7. It is possible to contract the life-history of Dipsacus sylvestris torsus into the limits of one year, if the seed be sown immediately it is ripe and the conditions be favourable. By this means an additional generation can be obtained each year; and it might perhaps be possible, by selection, to produce an annual twisted breed. However, so far as experiment goes at present, it appears that the annual character is developed at the expense of the biastrepsis; for in such plants there is little or no twisting of the stem.

8. The statement that, with a given hereditary tendency, a monstrosity becomes more marked the more favourable the conditions of life, and therefore the more vigorous the growth, is true not only for the biastrepsis of Dipsacus sylvestris, but is established for the most various plants and different monstrosities by the observations which I have made during the last ten years ${ }^{1}$.

1 Vide, Ueber die Abhängigkeit der Fasciation vom Alter bei zweijährigen Pflanzen, Botan. Centralblatt, Bd. 1xxvii, I899; and, Sur la culture des fasciations des espèces annuelles et bisannuelles, Revue générale de Botanique, Tom. xi, I899, p. 136 .

I am always ready to supply seed of Dipsacus sylvestris torsus, even in considerable quantity. I can generally supply specimens of twisted stems. 


\section{$2 \mathrm{BHL}$ Biodiversity Heritage Library}

Vries, Hugo de. 1899. "On biastrepsis in its relation to cultivation." Annals of botany 13, 395-420. https://doi.org/10.1093/oxfordjournals.aob.a088739.

View This Item Online: https://www.biodiversitylibrary.org/item/232524

DOI: https://doi.org/10.1093/oxfordjournals.aob.a088739

Permalink: https://www.biodiversitylibrary.org/partpdf/318545

\section{Holding Institution}

Smithsonian Libraries

\section{Sponsored by}

Biodiversity Heritage Library

\section{Copyright \& Reuse}

Copyright Status: Not in copyright. The BHL knows of no copyright restrictions on this item.

This document was created from content at the Biodiversity Heritage Library, the world's largest open access digital library for biodiversity literature and archives. Visit BHL at https://www.biodiversitylibrary.org. 